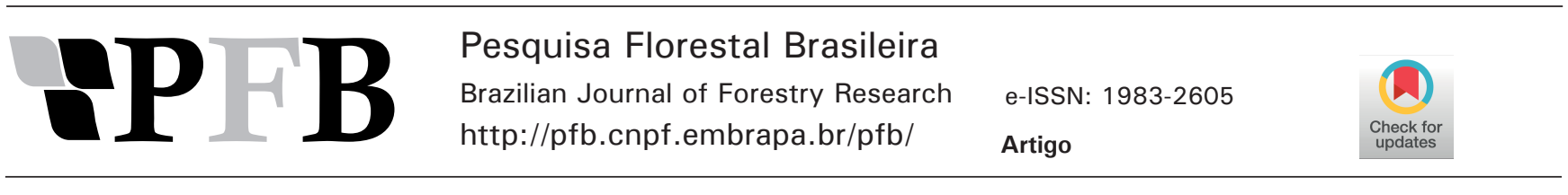

\title{
Eficiência de diferentes métodos para superação da dormência em sementes de Dimorphandra mollis
}

\author{
Francisco Ivo dos Santos Aguiar ${ }^{1 *}$ (D), Rafael Carvalho da Silva ${ }^{1}$ (D), Romário Martins Costa $^{2}$ (D), Clene dos Santos Reis ${ }^{3}$ (D), \\ Maryzélia Furtado de Farias ${ }^{3}$ (D), Luisa Julieth Parra-Serrano ${ }^{3}$ (D)
}

${ }^{1}$ Universidade Federal Rural do Rio de Janeiro, Rodovia BR 465, km 07, s/n Zona Rural, CEP 23890-000, Seropédica, RJ, Brasil

${ }^{2}$ Universidade Federal do Piauí, Campus Universitário Ministro Petrônio Portella, Ininga, CEP 64049-550, Teresina, PI, Brasil

${ }^{3}$ Universidade Federal do Maranhão, Centro de Ciências Agrárias e Ambientais, MA-230, km 04, S/N, Boa Vista, CEP 65500-000, Chapadinha, MA, Brasil

\section{"Autor correspondente:}

ivoaguia222@hotmail.com

Termos para indexação:

Árvores do cerrado

Quebra de dormência

Produção de mudas

Index terms:

Cerrado trees

Dormancy breaking

Seedling production

Histórico do artigo:

Recebido em 04/06/2019

Aprovado em 30/03/2020

Publicado em 21/10/2021
Resumo - Este trabalho objetivou determinar métodos eficientes para superação de dormência em sementes de Dimorphandra mollis Benth. As sementes foram coletadas em árvores matrizes do município de Buriti, MA, Brasil e foram submetidas aos seguintes tratamentos: controle (T1); escarificação mecânica com lixa $n^{\circ} 60$ (T2); escarificação química com soda cáustica a $98 \%$ por 15 min (T3); escarificação química com ácido sulfúrico $99,9 \%$ por 20 min (T4) e choque térmico com água (T5). Em casa de vegetação, foram dispostas 16 sementes por tratamento, divididas em quatro repetições, em delineamento inteiramente ao acaso. As avaliações foram iniciadas ao terceiro dia após o tratamento das sementes e estenderam-se por 17 dias após a semeadura. Avaliou-se o percentual de sementes emergidas e o índice de velocidade de emergência. Os tratamentos de escarificação mecânica com lixa (T2) e escarificação química com ácido sulfúrico (T4) foram eficientes para superar a impermeabilidade do tegumento nas sementes, sendo a escarificação mecânica o método mais seguro aos usuários para a superação da dormência das sementes.

\section{Efficiency of different methods for dormancy breaking in seeds of Dimorphandra mollis}

\begin{abstract}
This work aimed to determine efficient methods for dormancy breaking in Dimorphandra mollis Benth seeds. The seeds were collected from mother trees in the municipality of Buriti, Maranhão State, Brazil. They were submitted to the following treatments: control (T1); mechanical scarification with sandpaper No. 60 (T2); chemical scarification with $98 \%$ lye (sodium hydroxide) for 15 min (T3); chemical scarification with sulfuric acid $99.9 \%$ for 20 min (T4) and thermal-shock with water (T5). In a greenhouse, we used 16 seeds per treatment, divided into four replications, in a completely randomized design. The evaluations started on the third day after seeds were treated and it was carried out until 17 days after sowing. The percentage of emerged seeds and the emergence speed index were evaluate. The mechanical scarification treatment with sandpaper (T2) and the chemical scarification with sulfuric acid (T4) were efficient to overcome the seed coat impermeability, but the mechanical scarification is the safest method for users to overcome seed dormancy.
\end{abstract}




\section{Introdução}

A espécie florestal Dimorphandra mollis Benth, conhecida popularmente como fava d'anta, é nativa do Cerrado brasileiro e exibe grande importância em função de sua utilidade econômica e ecológica (Pacheco et al, 2010). Sua madeira é moderadamente densa (580 $\mathrm{kg} \mathrm{m}^{-3}$ ) e de durabilidade natural média, podendo ser usada para confecção de diversos produtos, como: tabuados, caixotaria, compensados, forros, painéis, brinquedos, lenha e carvão. Além disso, em decorrência de sua beleza, a árvore pode ser utilizada em projetos de paisagismo (Lorenzi, 1992; Campos Filho \& Sartorelli, 2015).

A espécie também possui importância nos processos de fertilização dos ecossistemas, pois suas raízes têm a capacidade de fixar nitrogênio no solo. Segundo Filizola (2013), essa árvore é comum em florestas primárias e secundárias, ocorrendo em solos pobres e degradados.

No entanto, empresas processadoras têm como foco comercial o aproveitamento de suas sementes para extração de princípios ativos, como: a rutina, a quercetina e a ramnose. De acordo com Souza et al. (2016) o setor industrial farmacêutico faz uso em grande escala do açúcar rumnose e dos flavonoides quercetina e rutina, sendo $50 \%$ da produção mundial, dessa última substância, extraída da fava d'anta.

Essa espécie não é cultivada no Brasil e toda a matéria-prima é extraída nas áreas de ocorrência natural, ao que parece, sem um programa de manejo, caracterizando-se como extrativismo predatório (Nunes et al., 2012). Mediante aos descasos com a reprodução da espécie de Dimorphandra mollis Benth, há grandes riscos de que elas sejam extintas (Masetto et al., 2014). Desta forma, surge a preocupação em se estabelecer procedimentos para a conservação da espécie, já que a sua propagação é seminal e as sementes apresentam dormência física do tipo tegumentar (Silva et al., 2011).

Em geral, a produção de mudas de espécies florestais tropicais com sementes duras, como é o caso da fava d'anta, é difícil (Castro et al., 2017). Essas sementes apresentam tegumentos duros e impermeáveis, dificultando o desenvolvimento do embrião, pelo impedimento da entrada de água e trocas gasosas eficientes com o ambiente além de retardar o processo germinativo (Castro et al., 2017). Com isso, D. mollis pode estar ameaçada, sendo necessário determinar meios eficientes para superação dessa dormência e procedimentos para a sua conservação e utilização sustentável (Martins et al., 2007; Fernandes et al., 2008).

A dormência em sementes é uma condição, em que, mesmo viáveis, elas não germinam, por se tratar de uma qualidade evolutiva para a perpetuação da espécie (Costa et al., 2010). Porém, pode ser considerada uma característica negativa quando o objetivo consiste na produção de mudas, sendo necessária a utilização de métodos de superação dessa dormência (Zwirtes et al., 2013).

Exitem diversas metodologias para realizar a quebra de dormência em sementes, porém os tratamentos mais eficientes vão depender dos tipos causais da dormência. Sendo assim, para cada espécie, haverá um ou mais métodos adequados (Tavares et al., 2015).

Os tratamentos com destaque na superação da dormência tegumentar em sementes florestais são: a escarificação química, a escarificação mecânica e a imersão em água quente. Vale ressaltar que o sucesso desses procedimentos também está ligado ao grau de dormência que varia entre espécies, origem e época de colheita (Lima et al,. 2013).

Em consideração à importância econômica da espécie e às limitações no processo de formação de mudas, este trabalho teve por objetivo determinar métodos eficientes para superação de dormência em sementes de Dimorphandra mollis Benth no intuito de contribuir para sua domesticação e manejo.

\section{Material e métodos}

As sementes utilizadas foram coletadas em 8 árvores matrizes selecionadas no município de Buriti, MA, localizado nas coordenadas geográficas $03^{\circ} 56^{\prime} 32^{\prime \prime S}$ e $45^{\circ} 55^{\prime} 30^{\prime} \mathrm{W}$. O clima predominante nesse município, segundo classificação de Köppen e Geiger, é o tropical, com inverno seco (Aw), com temperatura média de $27,3{ }^{\circ} \mathrm{C}$ e pluviosidade média anual de $1.556 \mathrm{~mm}$ (Climate-Data.org, 2018).

Com a finalização da coleta, as sementes foram levadas ao Laboratório de Água e Solo do Centro de Ciências Agrárias e Ambientais, da Universidade Federal do Maranhão. Neste laboratório, todo o material coletado foi beneficiado, sendo as sementes retiradas das vagens, lavadas com solução de hipoclorito de sódio a $1 \%$, lavadas em água corrente e, por último, colocadas para secar em papel toalha por $24 \mathrm{~h}$. Posteriormente, as sementes foram submetidas aos seguintes tratamentos: 
$\mathrm{T} 1$ = controle: sementes sem escarificar;

$\mathrm{T} 2$ = escarificação mecânica com lixa $\mathrm{n}^{\circ} 60$ : as sementes foram friccionadas com lixa $n^{\circ} 60$, manualmente, até o desgaste visível do tegumento no lado oposto à micrópila;

T3 = escarificação química com hidróxido de sódio (soda cáustica) a 98\% por 15 min: as sementes foram colocadas em solução com $100 \mathrm{~g}$ de soda cáustica e água $(400 \mathrm{~mL})$ durante $15 \mathrm{~min}$, em seguida foram lavadas em água corrente e colocadas para secar à sombra;

T4 = escarificação química com ácido sulfúrico 99,9\% por 20 min: imergiu-se as sementes em $150 \mathrm{~mL}$ de ácido sulfúrico;

T5 = choque térmico com água: utilizou-se $400 \mathrm{~mL}$ de água em um becker aquecido em chapa até atingir $100{ }^{\circ} \mathrm{C}$, onde as sementes foram imersas por $10 \mathrm{~min}$ e, posteriormente, lavadas com água gelada.

No experimento, foram utilizadas 16 sementes por tratamento, sendo divididas em quatro repetições, dispostas em delineamento inteiramente casualizado.

Após a escarificação, os tratamentos foram alocados em casa de vegetação com $50 \%$ de luminosidade e temperatura $\pm 28^{\circ} \mathrm{C}$. As sementes foram semeadas em bandejas de poliestireno de fundo perfurado, contendo areia lavada, peneirada e esterilizada. As sementes foram regadas diariamente, de acordo com a necessidade de água.

As contagens do número de plântulas emergidas foram iniciadas no terceiro dia e estenderam-se até quando não houvesse mais incidência de germinação de sementes, ou seja, aos 17 dias após a semeadura. As características avaliadas foram: percentual de sementes emergidas e índice de velocidade de emergência.

Os dados coletados na casa de vegetação foram digitados em planilha eletrônica e transformados em porcentagem, sendo também calculado o índice de velocidade de emergência, utilizado a Equação 1, proposta por Maguire (1962).

$$
\mathrm{IVE}=(\mathrm{N} 1 / \mathrm{D} 1)+(\mathrm{N} 2 / \mathrm{D} 2)+\ldots+(\mathrm{Nn} / \mathrm{Dn})
$$

Onde: IVE = índice de velocidade de emergência; $\mathrm{N}=$ número de sementes emergidas e computadas da primeira à última contagem; e $\mathrm{D}=$ número de dias da semeadura da primeira à última contagem.
Os dados foram submetidos à análise de variância para delineamento inteiramente casualizado, sendo a comparação entre as médias feita pelo teste de Tukey a $5 \%$ de probabilidade, com auxílio do programa estatístico InfoStat $^{\circledR}$ v. 2008.

\section{Resultados}

O percentual de emergência das sementes de Dimorphandra mollis variaram entre os tratamentos, sendo os melhores escarificação mecânica e imersão em ácido sulfúrico, os quais não diferiram estatisticamente entre si (Figura 1). Os demais tratamentos prégerminativos não foram tão eficientes e não diferiram do tratamento controle. Na contabilização de todas as sementes, $79,7 \%$ germinaram e $20,3 \%$ apodreceram, devido à colonização de fungos.

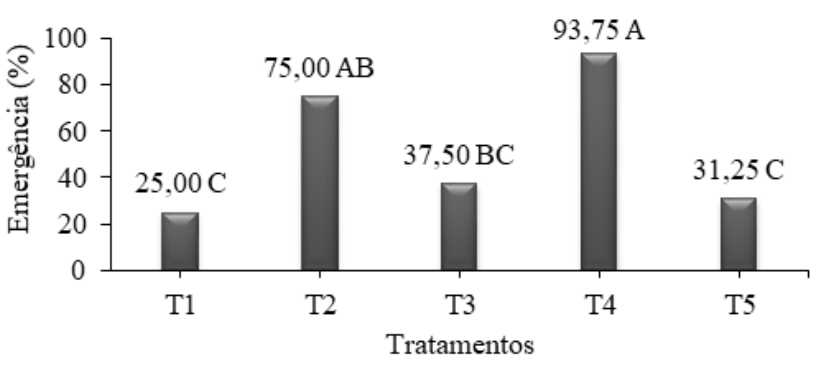

Figura 1. Valores médios de porcentagens de emergência de sementes de Dimorphandra mollis tratadas para quebra de dormência. T1 - controle; T2 - escarificação mecânica; T3 - imersão em soda cáustica; T4 - imersão em ácido sulfúrico; e T5- choque térmico com água. Médias seguidas pela mesma letra não diferem estatisticamente pelo teste de Tukey $(p>0,05)$.

Figure 1. Averages percentages of seeds emergency of Dimorphandra mollis treated for dormancy breaking. T1 control; T2 - mechanical scarification; T3 - immersion in lye (sodium hydroxide); T4 - immersion in sulfuric acid; and T5 - thermal shock with water. Means followed by the same letter did not differ statistically by Tukey test $(p>0.05)$.

Em relação ao índice de velocidade de emergência, o maior valor foi observado na escarificação mecânica com lixa, o qual diferiu estatisticamente dos demais tratamentos (Figura 2). Os outros tratamentos mostraramse ineficazes, já que não diferiram do controle, sendo o tratamento com choque térmico o que apresentou menor índice de velocidade de emergência (IVE). 


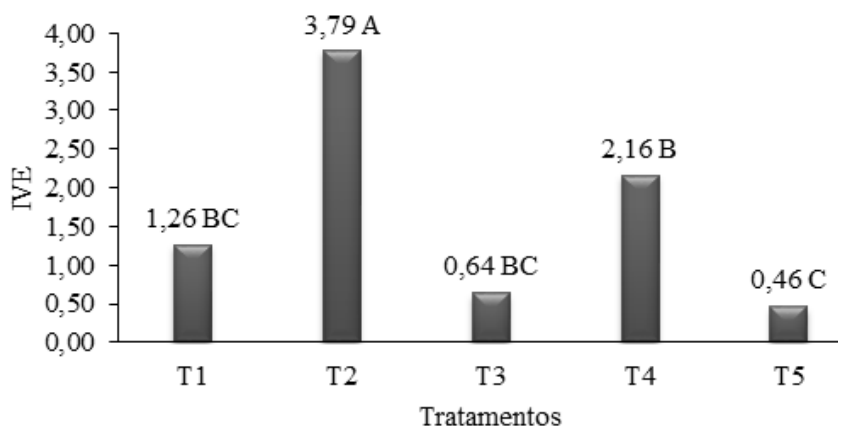

Figura 2. Valores médios dos índices de velocidade de emergência (IVE) de sementes de Dimorphandra mollis tratadas para quebra de dormência. T1 - controle; T2 escarificação mecânica; T3 - imersão em soda cáustica; T4 - imersão em ácido sulfúrico; e T5 - choque térmico com água. Médias seguidas pela mesma letra não diferem estatisticamente pelo teste de Tukey $(p>0,05)$.

Figure 2. Means values of the emergence speed index (IVE) of seeds of Dimorphandra mollis treated for dormancy breaking. T1 - control; T2 - mechanical scarification; T3 - immersion in lye (sodium hydroxide); T4 - immersion in sulfuric acid; and T5 - thermal shock with water. Means followed by the same letter did not differ statistically by Tukey test $(p>0.05)$.

\section{Discussão}

Os tratamentos com escarificação mecânica e imersão em ácido sulfúrico foram superiores aos demais tratamentos, quando considerado o percentual de emergência. Silva et al. (2011) obtiveram resultados semelhantes ao avaliarem o potencial germinativo de sementes de Dimorphandra mollis tratadas com diferentes métodos de escarificação, fortalecendo o indicativo desses serem os métodos mais adequados para superação da dormência das sementes dessa espécie.

Zwirtes et al. (2013) consideram a utilização de choque térmico com água um método de baixo custo para quebra de dormência, que apresenta uma eficiência relativa para algumas leguminosas. No entanto, no presente caso, esse método não apresentou resultados razoáveis para a superação da dormência em sementes de fava d'anta, possivelmente, pela alta temperatura ter afetado os tecidos dos embriões, danificando-os, resultado que corrobora aqueles obtidos por Oliveira et al. (2008). De forma semelhante, a utilização do tratamento com soda cáustica proporcionou maior germinação em sementes de Leucena leucocephala (Araújo et al., 2013), porém não mostrou tal eficiência para $D$. mollis, talvez por esta apresentar tegumento mais resistente, necessitando assim de mais tempo de exposição ao produto.

A utilização de ácido sulfúrico é comum para a quebra da dormência tegumentar. Entretanto, Carvalho et al. (2016) salientam que a sua eficiência está relacionada com o tempo de exposição ao ácido e à espécie. Hermansen et al. (2000) quebraram a dormência de sementes de $D$. mollis com imersão em ácido sulfúrico por 45 a 90 min. Mas, baseado no presente trabalho, 20 min seriam suficientes para superar a dormência, otimizando o processo (Figura 1). O sucesso desse método ocorre devido ao ácido sulfúrico reduzir a espessura do tegumento das sementes de fava d'anta, permitindo a entrada de água e facilitando a germinação.

A escarificação mecânica consiste em um dos métodos mais simples e eficientes para superação de dormência, sobretudo, para sementes que apresentam tegumento duro (Silva et al., 2011; Araújo et al., 2013). Resultados satisfatórios, utilizando esse método, em sementes de D. mollis, também foram encontrados por Oliveira et al. (2008). Esse tipo de escarificação aumenta a permeabilidade da água, retirando parte do tegumento, o que influencia o metabolismo e a dormência das sementes (Lopes et al., 2006).

A eficiência do ácido sulfúrico e da escarificação mecânica na superação de dormência e promoção da germinação de sementes de espécies florestais é comprovada. Alguns dos trabalhos que atestam essas informações são os estudos realizados por Lima et al. (2013), por Masetto et al. (2014) e por Freire et al. (2016).

Quando se compara os resultados entre escarificação mecânica e imersão em ácido sulfúrico, nota-se uma redução na velocidade de emergência das sementes tratadas com ácido sulfúrico em relação às escarificadas com lixa (Figura 2). Segundo Santos (2011), a utilização de ácido sulfúrico para a escarificação de sementes de algumas espécies florestais pode provocar a degradação da semente ou causar danos ao embrião, reduzindo a velocidade de emergência das plântulas, o que justificaria o tratamento de ácido sulfúrico ter apresentado menor percentual.

Ressalta-se que uma grande parte das sementes apodreceu antes mesmo da germinação. Segundo Giuliano et al. (2005), esse apodrecimento ocorre porque as sementes de fava d'anta são portadoras de microrganismos que interferem na germinação e causam a sua morte. 
Apesar de existirem muitos trabalhos sobre a germinação de espécies nativas brasileiras (Silva et al., 2015; Carlos et al., 2017; Oliveira et al., 2018), esse número é ainda muito pequeno em relação à grande diversidade da flora arbórea nacional. Para Oliveira Júnior et al. (2018), estudos visando o planejamento e desenvolvimento de técnicas e manejo para a recuperação de ambientes naturais e até mesmo para o suprimento de novos produtos para o setor agroindustrial, são muito importantes.

\section{Conclusões}

Embora o tratamento com ácido sulfúrico $(99,9 \%$ p.a.) tenha apresentado bom resultado para a quebra de dormência de sementes de Dimorphandra mollis, este é extremamente perigoso e oneroso, principalmente para pessoas sem treinamento e habilidade para manuseá-lo. Além disso, esse produto é poluidor do meio ambiente. Dessa forma, a escarificação mecânica das sementes se mostra uma alternativa viável, eficaz e, sobretudo, segura para os manipuladores e para o meio ambiente.

\section{Referências}

Araújo, A. V. et al. Métodos de superação de dormência para a produção de mudas de Leucaena leucocephala (Lam.) de Wit. Enciclopédia Biosfera, v. 9, n. 17, p. 1898, 2013.

Campos Filho, E. M. \& Sartorelli, P. A. R. Guia de árvores com valor econômico. São Paulo: Agroicone, 2015. 67 p.

Carlos, J. et al. Efeito de dois tipos de quebra de dormência na germinação de guapuruvu (Schizolobium parahyba). Natural Resources, v. 7, n. 2, p. 43-51, 2017. http://doi.org/10.6008/ SPC2237-9290.2017.002.0005.

Carvalho, C. C. et al. Escarificação, temperatura e fotoperíodo na germinação de sementes de Balizia pedicellaris (DC.) Barneby \& J.W. Grimes (fabaceae). Pesquisa Botânica, v. 1, n. 69, p. 249-261, 2016.

Castro, D. S. et al. Caracterização da testa de sementes de Apuleia leiocarpa (VOGEL J. F. MACBR) após superação de dormência. Ciência Florestal, v. 27, n. 3, p. 1061-1068, 2017. http://dx.doi. org/10.5902/1980509828681.

Climate-Data.Org : clima buriti. Disponível em: $<$ https://pt.climatedata.org/america-do-sul/brasil/maranhao/buriti-44086/>. Acesso em: 20 nov. 2018.

Costa, P. A. et al. Quebra de dormência em sementes de Adenanthera pavonina L. Pesquisa Agropecuária Tropical, v. 40, n. 1, p. 83-88, 2010. http://dx.doi.org/10.5216/pat.v40i1.4092.
Fernandes, L. A. et al. Níveis de nitrogênio, fósforo e potássio para a produção de mudas de fava d'anta (Dimorphandra mollis Benth). Revista Brasileira de Plantas Medicinais, v. 10, n. 1, p. 94-99, 2008.

Filizola, B. C. Boas práticas de manejo para o extrativismo sustentável da fava d'anta. Brasília, DF: Embrapa Recursos Genéticos e Biotecnologia; Instituto Sociedade, População e Natureza, 2013. 76 p.

Freire, J. M. et al. Superação de dormência de dementes de Albizia pedicellaris (DC.) L. Rico. Floresta e Ambiente, v. 23, n. 2, p. 251257, 2016. http://dx.doi.org/10.1590/2179-8087.104514.

Giuliano, I. et al. Identificação de fungos em sementes de Dimorphandra mollis e efeito de diferentes tratamentos. Fitopatologia Brasileira, v. 30, n. 5, p. 553, 2005. http://dx.doi.org/10.1590/S010041582005000500021.

Hermansen, L. A. et al. Variability in seed coat dormancy in Dimorphandra mollis. Seed Science and Technology, v. 28, n. 3, p. 567-580, 2000.

Lima, J. S. et al. Métodos de superação de dormência em sementes de flamboyant (Delonix regia). Revista Verde, v. 8, n. 1, p. 104109, 2013.

Lopes, J. C. et al. Tratamentos para acelerar a germinação e reduzir a deterioração das sementes de Ormosia nitida Vog. Revista Árvore, v. 30, n. 2, p. 171-177, 2006. http://dx.doi.org/10.1590/S010067622006000200003 .

Lorenzi, H. Árvores brasileiras: manual de identificação e cultivo de plantas arbóreas nativas do Brasil. Nova Odessa: Plantarum. 1992. $2 \mathrm{v}$.

Maguire, J. D. Speed of germination-aid selection and evaluation for seedling emergence and vigor. Crop Science, v. 2, n. 2, p. 176177, 1962.

Martins, L. V. et al. Prospecção fitoquímica preliminar de Dimorphandra mollis Benth. (Fabaceae-Mimosoideae). Revista Brasileira de Biociências, v. 5, n. 2, p. 828-830, 2007.

Masetto, T. E. et al. Germinação de sementes de Dimorphandra mollis Benth.: efeito de salinidade e condicionamento osmótico. Revista Brasileira de Biociência, v. 12, n. 3, p. 127-131, 2014.

Nunes, J. D. et al. O extrativismo da fava d'anta (Dimorphandra mollis Benth.) na região do Norte de Minas Gerais. Revista Brasileira de Plantas Medicinais, v. 14, n. 2, p. 370-375, 2012. http://dx.doi.org/10.1590/S1516-05722012000200018.

Oliveira Júnior, A. B. et al. Identificação de dormência tegumentar em sementes florestais através do estudo da curva de embebição. Revista Intercâmbio, v. 11, n. 1, p. 1-13, 2018.

Oliveira, D. A. et al. Potencial germinativo de sementes de favad'anta (Dimorphandra mollis Benth. - Fabaceae: Mimosoideae) sob diferentes procedências, datas de coleta e tratamentos de escarificação. Revista Árvore, v. 32, n. 6, p. 1001-1009, 2008. http:// dx.doi.org/10.1590/S0100-67622008000600005.

Oliveira, K. J. B. et al. Quebra de dormência de sementes de Delonix regia (Fabaceae). Revista de Ciências Agrárias, v. 41, n. 3, p. 707716, 2018. http://dx.doi.org/10.19084/RCA17302 . 
Pacheco, M. V. et al. Germination and vigor of Dimorphandra mollis benth. seeds under different temperatures and substrates. Revista Árvore, v. 34, n. 2, p. 205-213, 2010. http://dx.doi.org/10.1590/ S0100-67622010000200002.

Santos, A. L. F. Avaliação de métodos para superação de dormência de sementes leguminosas arbóreas utilizadas na recuperação de áreas degradadas. Seropédica: Embrapa Agrobiologia, 2011. 32 p.

Silva, E. S. et al. Comparação entre métodos de quebra de dormência de sementes de Dimorphandra mollis Benth. submetidas a duas condições de luminosidade após armazenamento. Enciclopédia Biosfera, v. 7, n. 13, 2011.
Silva, L. L. et al. Escarificação de sementes para desenvolvimento em plântulas de açaizeiro. Revista Agro@mbiente On-line, v. 9, n. 1, p. 72-78, , 2015. http://doi.org/10.5327/Z1982-8470201500011909.

Souza, M. F. et al. Emergência e desenvolvimento inicial de sementes de Dimorphandra mollis Benth. em campo. Revista Brasileira de Plantas Medicinais, v. 18, n. 1, p. 186-190, 2016. http://dx.doi. org/10.1590/1983-084X/15_066.

Tavares, D. V. L. et al. Metodologia de quebra de dormência em sementes de sucupira-branca. Revista Conexão Eletrônica, v. 12, n. 1, p. 1-9, 2015.

Zwirtes, A. L. et al. Métodos de superação de dormência em sementes de flamboyant. Pesquisa Florestal Brasileira, v. 33, n. 74, p. 463467, 2013. https://doi.org/10.4336/2013.pfb.33.76.568. 